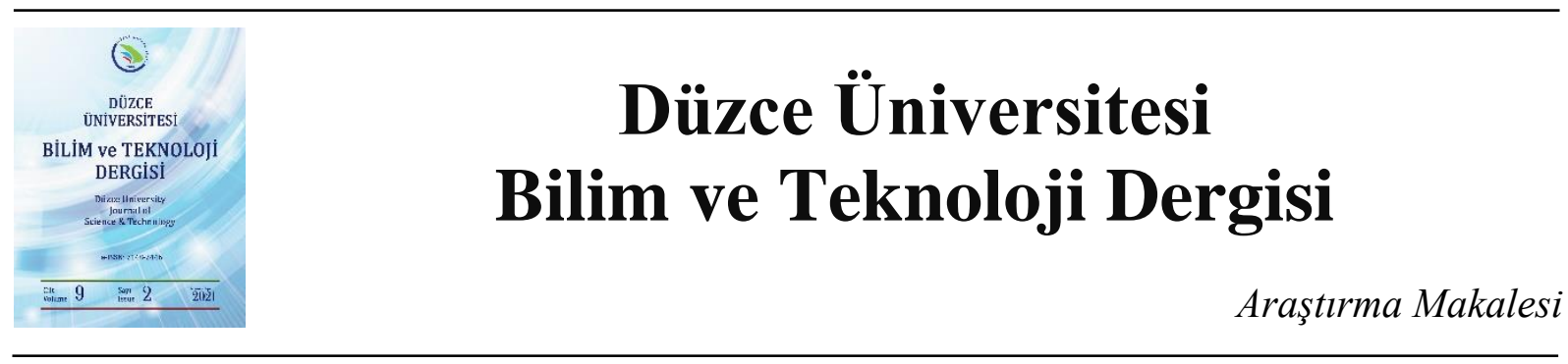

\section{Darıderesi II Göleti Dip Savak Yapısının Fluent ile Sayısal Modellenmesi}

\author{
Tuba AYDIN ${ }^{a}$, (DD Dilek TAYLAN ${ }^{a}$ * \\ ${ }^{a}$ Inş̧aat Mühendisliği Bölümü, Mühendislik Fakültesi, Süleyman Demirel Üniversitesi, Isparta, TÜRKİYE \\ * Sorumlu yazarın e-posta adresi: dilektaylan@sdu.edu.tr
}

DOI: 10.29130/dubited.759774

\begin{abstract}
ÖZET
Hidrolik yapılar ve hidrolik yapıların farklı öğeleri için, hidrolik hesaplamalar çeşitli deneysel çalışmalara başvurarak yapılabilmektedir. Yapılan deneysel çalışmalar ile hidrolik hesaplamalar desteklenmeye çalışılmaktadır. Ancak, deneysel çalışmaların maliyetli olması ve uzun bir zamana yayılması sebebi ile, 3 boyutlu simülasyon programları tercih edilmektedir. Hidrolik yapılar için, hesaplamalı akışkanlar dinamiği yöntemi (HAD) ile çalışan programların kullanılmaya başlanması ile deneysel çalışmalara olan ihtiyaç gittikçe azalmıştır. Sonlu elemanlar, sonlu hacimler gibi sayısal yöntemlerin de katkısıyla, akış ayrıntılı bir şekilde incelenebilmektedir. Bu çalışma, Isparta'da bulunan, içme ve kullanma suyu ihtiyacını karşılamak için yapılan, Darıderesi II Göleti'ne ait dip savak yapısı için yapılmıştır. Ölü hacim üzerindeki suyun mansaba iletilmesini sağlayan dip savak yapısında türbülanslı ve laminer akım halleri incelenmiştir. Dip savak yapısı, sonlu elemanlar ile çalışan ANSYS programı Fluent modülü ile modellenmiştir. Geliştirilen 3 boyutlu modele ait, kesitte meydana gelecek olan toplam basınç, hız büyüklüğü ve boruya ait kesme gerilme değerleri incelenmiştir. Türbülanslı akım hali için elde edilen kinematik büyüklükler hidrolik şartnamede verilen sınır şartlarına daha yakın değişimler göstermiştir. Dip savak yapılarında laminer akım hali yerine türbülanslı akım halinin seçilmesi daha uygun bulunmuştur.
\end{abstract}

Anahtar Kelimeler: Baraj, Dip Savak, HAD, ANSYS, Saylsal Modelleme.

\section{Numerical Modeling of the Deep Sluice Structure of Darıderesi II Pond by Fluent}

\begin{abstract}
Hydraulic calculations can be made by referring to various experimental studies for hydraulic structures and different components of hydraulic structures. Hydraulic calculations are tried to be supported by experimental studies. However, 3D simulation programs are preferred because experimental studies are costly and spread over a long time. For hydraulic structures, the need for experimental studies has gradually decreased with the use of programs that work with the computational fluid dynamics method CFD. Flow can be examined in detail with the contribution of numerical methods such as finite elements, finite volumes. This study was carried out for the deep sluice structure of Darıderesi II Pond in Isparta, which was built to meet domestic water need. The turbulent and laminar flow conditions in the deep sluice that enable the transfer of water over the dead volume to the downstream were investigated. The deep sluice was modeled with the ANSYS program Fluent module, which works with finite elements. In the developed 3D model, the total pressure, velocity and shear stress values of the pipe that will occur in the cross section were examined. Kinematic quantities obtained for turbulent flow showed closer changes to the boundary conditions given in the hydraulic specification. It has been found more appropriate to choose turbulent flow instead of laminar flow in deep sluice structures.
\end{abstract}

Keywords: Dam, Deep Sluice, CFD, ANSYS, Numerical Modelling. 


\section{GIRIS}

Enerji üretimi, içme ve kullanma suyu temini, sulama suyu temini, taşkın kontrolü, rekreasyon gibi farklı yapım amaçları olan barajlarda, çok büyük bir su kütlesi baraj gövdesi ile tutulmaktadır. İnşaat sırasında çalışma bölgesini kuru tutmak amacıyla suyun yönünün değiştirilmesi için yapılan derivasyon tünelleri daha sonra işletme sırasında ölü hacim üzerindeki suyu boşaltmayı sağlayan ve tünel şseklinde inşa edilen dip savaklara dönüştürülen ve her baraj yapısında bulunan yardımcı elemanlardır. Baraj yapım amacına bağlı olarak farklı boyutlarda yapılan dip savaklarda kavitasyon olayı istenmeyen bir durumdur ve gerek deneysel gerekse de hesaplamalı olarak yapılan çalışmalarla bu olayın gerçekleşmemesi için öneriler sunulmaktadır. Deneysel çalışmalar fazla zaman aldığı ve maliyetleri yüksek olduğu için hesaplamalı akışkanlar dinamiği (HAD) yöntemi daha fazla tercih edilir hale gelmiştir ve son yıllarda farklı alanlardaki hidrolik modellemelerde sıklıkla kullanılmaktadır.

Aydın vd. [1], HAD ile Ilısu Barajı dip savağını modellemişler ve elde edilen sonuçların \%2-3 oranında hata payı ile deneysel sonuçlarla uyumlu olduğunu söylemişlerdir. Aynı zamanda HAD daha az zaman kaybı ve maliyete sahip bir yöntem olarak önerilmiştir.

Benzer şekilde Li vd. [2], mevcut bir dolu savağın yanı sıra yardımcı bir dolu savak tasarımı için HAD yöntemini kullanmışlar ve hidrolik yapıların tasarımında sağladığı kolaylıklar bakımından bu yöntemi tavsiye etmişlerdir.

Alihosseini ve Thamsen [3], tam dolu olmayan dairesel kesitli atık su borularının serbest yüzeyli akış prensiplerine göre modellenmesi için HAD kullanmışlar ve deneysel sonuçlarla karşılaştırmışlardır. HAD ile elde ettikleri sonuçların bağıl hatasını \%10’un altında bulmuşlardır.

Yaylacı ve Terzi [4], ANSYS ve ABAQUS programlarını kullanarak, birbirine bağlı rijit bir panç ile elastik düzlem olan, iki tabakanın simetrik temas problemini çözmeye çalışmışlardır. Temas problemlerinde, ANSYS gibi sonlu elemanlar alt yapısı ile çalışan bir programdan elde edilen sonuçlar ile analitik yöntem kullanılarak elde edilen sonuçları karşılaştırmışlardır. Sonlu elemanlar ve analitik yöntemden elde edilen sonuçların, iyi bir uyum gösterdiğini belirtmişlerdir.

Yılmaz ve Çiçek [5], iki farklı gemi test pervanesinin analizlerini yapıp, performanslarını incelemişlerdir. Pervanelere ait analizleri, ANSYS programı ile HAD yöntemi ile yapmışlardır. Elde edilen analiz sonuçlarını ve performanslardaki hata payını, yapılan diğer çalışmalardaki analiz sonuçları ile karşılaştırmışlardır. Performanslardaki hata payının, \%1 ve \%3 arasında değişiklik gösterdiğini belirtmişlerdir.

Benzer şekilde Beg vd. [6], kentsel atık su sistemindeki boru bağlantılarındaki akış özelliklerini modellemek için HAD kullanmışlardır ve Coimbra Üniversitesi hidrolik laboratuvarındaki deneysel çalışmalarla mukayese etmişlerdir. Özellikle atık su sistemlerindeki katı madde hareketini modellenmesi üzerine yüksek doğrulukta sonuçlar elde etmişlerdir.

Lopes vd. [7], atık su sistemleri basınçlı olması durumunda boru içerisindeki akımı deneysel ve sayısal olarak modellemişlerdir. HAD ile basınç akış özelliklerini belirlemeye çalışmışlar ve daha büyük akım hızları için sonuçların türetilebileceğini söylemişlerdir.

Kumar ve Pentakota [8], nükleer enerji santrallerinde kullanılan boru dirseklerindeki korozyon ve erozyon durumlarını incelemek için HAD kullanmışlardır. Çapsal basınç katsayısı için tahmin değerlerinin şartnamelerle uyumlu olduğunu belirtmişlerdir.

Bütün bu çalışmalar göz önüne alındığında, HAD hidrolik hesaplar yapılırken hem basınçlı borularda hem de açık kanallarda tercih edilen bir yöntem haline gelmiştir. Deneysel çalışmaların çok fazla zaman aldığı ve aynı zamanda maliyetli olması durumu, HAD ile çalışan simülasyon programlarının daha çok tercih edilmesine sebep olmuştur. 
Son yıllarda mühendislik çalışmalarında çeşitli analiz ve simülasyonların yapılabildiği ANSYS, sonlu elemanlar yöntemi kullanılarak numerik çözümler yapan bir program olmakla birlikte, çok farklı disiplinlerde çalışan kullanıcıların ortak bir çalışma alanında buluşmasını sağlamaktadır. Bu çalışmada akışkanlar dinamiği temel denklemleri ile, 2 boyutlu ve 3 boyutlu modellerin akış hareketini inceleyen ANSYS programının Fluent modülü kullanılarak, Darıderesi II Göleti dip savak yapısı için türbülanslı ve laminer akım oluşması durumları incelenmiştir. Her iki durum için elde edilen 3 boyutlu modellere ait, kesitte meydana gelecek olan toplam basınç, hız büyüklügü ve boruya ait kesme gerilme değerlerinin değişimi irdelenmiştir.

\section{MATERYAL VE METOT}

\section{A. DARIDERESII II GÖLETİ DIPP SAVAK YAPISI}

Darıderesi-II Göleti, Isparta ilinin yaklaşık 4 km güneyinde bulunan Darıderesi Köyü, Darı Deresi üzerindedir. Isparta ilinin içme suyunu karşılayan Darıderesi-I Göletinin $2.5 \mathrm{~km}$ membasında aynı dere üzerinde, yer almaktadır. Darıderesi-II Göleti, bölgedeki içme ve kullanma suyu ihtiyacını karşılamak amacıyla yapılmıştır.

Tablo 1'de, Darıderesi II Göleti, dip savak yapısı özellikleri bulunmaktadır.

Tablo 1. Darıderesi II Göleti Dip Savak Yapısı Özellikleri

Gölet Adı:

\begin{tabular}{|c|c|}
\hline Dipsavak Yeri: & Sağ Sahil \\
\hline Dipsavak Tipi: & Kademeli \\
\hline Dipsavak Çıkış Kotu: & $1105 \mathrm{~m}$ \\
\hline Pompa Deposu Eksen Kotu: & $1136 \mathrm{~m}$ \\
\hline Birim Debi $\left(Q_{\text {birim }}\right):$ & $1.50 \mathrm{~m}^{3} / \mathrm{s}$ \\
\hline Dip savak Cebri Boru Çapı $\left(D_{c e b r i}\right)$ : & $1.00 \mathrm{~m}$ \\
\hline Derivasyon Tüneli Çapı $\left(D_{\text {tünel }}\right)$ : & $3.00 \mathrm{~m}$ \\
\hline Dirsek Çap1 $\left(D_{\text {dirsek }}\right):$ & $2.00 \mathrm{~m}$ \\
\hline Tehlike Vanası Çapı $\left(D_{t v}\right):$ & $1.10 \mathrm{~m}$ \\
\hline İçme Suyu Ayar Vanası Çap1 $\left(D_{\text {aviçme }}\right)$ : & $1.00 \mathrm{~m}$ \\
\hline Dereye Deşarj Ayar Vanası Çap1 $\left(D_{\text {avdere }}\right):$ & $1.00 \mathrm{~m}$ \\
\hline Dereye Deşarj Branşman Cebri Boru Çap1 $\left(D_{\text {anaboru }}\right)$ : & $1.00 \mathrm{~m}$ \\
\hline İçme Suyu Branşman Cebri Boru Çapı $\left(D_{\text {branșman }}\right)$ : & $1.00 \mathrm{~m}$ \\
\hline İçme Suyu Cebri Boru Çapı $\left(D_{i c ̧ m e}\right):$ & $1.20 \mathrm{~m}$ \\
\hline
\end{tabular}

Tablo 1'de verilen özelliklerin yanında, gölete ait dip savak yapıs1 $624 \mathrm{~m}$ uzunluğunda olup, bu yap1 Isparta'nın içme ve kullanma suyu ihtiyacını hazne kısmından alıp mansap kısmına aktararak karşılamaktadır.

\section{B. HESAPLAMALI AKIȘKANLAR DINAMIĞİ (HAD) YÖNTEMI}

HAD, akış hareketlerini modellemek için çeşitli denklemlerin oluşturulmasında ve çözülmesinde etkili olarak kullanılan bir yöntemdir [9]. HAD, akışkanların hareketinin ve özelliklerinin gerçeğe en yakın şekilde tahmini için kullanılır. HAD ile deneysel çalışmalar arasındaki temel fark, HAD ile akış fiziği daha iyi bir şekilde kavranabilmektedir. Laboratuvarda, deneysel araçlarda birçok belirsizlik meydana gelebildiği için HAD ile bu belirsizlik en aza indirilmektedir [10-11]. 
Aynı zamanda HAD alt yapısı ile çalışan paket programlar sayesinde, oluşturulan modeller kısa zamanda çözüme ulaşmaktadır. Ayrıca, deneysel bir ortama ya da pahalı ekipmanlara ihtiyaç duyulmaması da bu yöntemle ile çalışan programları daha ulaşılabilir yapmaktadır.

HAD sayısal çözümü, matematiksel modellere karşıllk gelen denklemleri çözmeyi amaçlar. $\mathrm{Bu}$ matematiksel modeller, fiziğin koruma yasalarına dayanan akışkan hareketinin denklemleridir. Sıvı akışı problemindeki akış parametrelerini çözmek için, kütlenin korunumu, momentumun korunumu ve enerjinin korunumu olmak üzere üç denklem bulunmaktadır [11].

Kütlenin korunumu denklemi, Versteeg ve Malalasekera [12]'e göre akışkan bir maddenin kütlesinin korunması, kütle dengesine dayanmaktadır;

$\mathrm{t}$ anında akışkanın kütlesi $=\mathrm{t}+\mathrm{dt}$ anında akışkanın kütlesi

$\mathrm{u}_{1} \mathrm{~A}_{1}=\mathrm{u}_{2} \mathrm{~A}_{2}$

Yukarıdaki Denklem 1 sıkıştırılamaz akışkanlar için geçerliyken, Denklem 2 ise sıkıştırılabilen akışkanlar için geçerlidir.

$\rho_{1} u_{1} A_{1}=\rho_{2} u_{2} A_{2}$

Denklem 1 ve 2'de verilen, u parametresi hız vektörünü, $\rho$ akışkanın özgül kütlesini, A ise kesit alanını ifade etmektedir.

Momentumun korunumu denklemi ise, Newton'un ikinci yasası, sıvı bir parçacığın momentumundaki değişim oranını (artma miktarı) parçacık üzerindeki kuvvetlerin toplamına eşit olduğunu belirtir [12].

Momentum denklemi aşağıdaki gibidir;

$\sum_{\mathrm{F}}=\rho \mathrm{u}_{2} \mathrm{dA}_{2} \underset{\mathrm{u}_{2}}{\rightarrow_{2}}-\rho \mathrm{u}_{1} \mathrm{dA}_{1} \underset{\mathrm{u}_{1}}{\vec{x}_{1}}$

Denklem 3'te bulunan, $\overrightarrow{\mathrm{u}}_{2}$ vektörel hızı, F kuvveti temsil ederken, diğer parametreler kütlenin korunumu denkleminde yer alan parametreler ile aynıdır.

Enerjinin korunumu denklemi akışkanlar için aşağıdaki şekilde kullanılmaktadır;

$\mathrm{t}$ anında sistemin enerjisi $+\mathrm{dt}$ zaman aralığında yapılan iş $=\mathrm{t}+\mathrm{dt}$ anında sitemin enerjisi

$\frac{1}{2 \mathrm{~g}} \mathrm{u}_{1}^{3} \mathrm{dA}_{1}+\frac{\mathrm{P}_{1}}{\mathrm{\gamma}} \mathrm{u}_{1} \mathrm{dA}_{1}+\mathrm{z}_{1} \mathrm{u}_{1} \mathrm{dA}_{1}=\frac{1}{2 \mathrm{~g}} \mathrm{u}_{2}^{3} \mathrm{dA}_{2}+\frac{\mathrm{P}_{1}}{\mathrm{\gamma}} \mathrm{u}_{2} \mathrm{dA}_{2}+\mathrm{z}_{1} \mathrm{u}_{2} \mathrm{dA}_{2}+\frac{1 \mathrm{dS}}{\mathrm{\gamma}}$

Denklem 4'te bulunan parametrelerden, $\mathrm{P}$, kesitteki statik basınç değerini; $\mathrm{t}$, zamanı; $\mathrm{\gamma}$, akışkanın özgül ağırlı̆̆ını; g, yer çekim ivmesini; $\mathrm{z}$, düşey mesafeyi; $\mathrm{S}$ ise sürtünmeye bağlı oluşacak isı enerjisini temsil etmektedir [12].

\section{LAMINER VE TÜRBÜLANSLI AKIM}

Genel olarak, doğada karşılaşılan akımlar çalkantılıyken, deneysel düzeneklerde modellenen akımlar ise daha kararlı yapıdadırlar. Birbirine paralel düzgün akım çizgileriyle belirtilen akış hareketi laminer akım olarak adlandırılmaktadır. Düşük hızlarda yüksek viskoziteli akışkanların akım hareketi genellikle laminerdir. Çalkantılı akışkan hareketi ise yüksek hızlarda meydana gelir ve türbülanslı denen akış değişimleriyle ifade edilir. 
Basınçlı borulardaki akış incelendiğinde, akışkan hareketinin; akım hızının düşük olduğu durumlarda kararlı bir yapıda olduğu, hız belli bir değerin üzerine çıktığında ise çalkantılı hale döndüğü görülmüştür. Akım çizgilerinin düzgün ve birbirine paralel yapıda olması halinde akışın laminer olduğu; akışta hız değişimleri varsa ve akış çalkantılı bir durumdaysa, akışın türbülanslı olduğu söylenir. Pratikte karşılaşılan çoğu akış türbülanslıdır. Laminer akımlarla, yağ gibi viskoz akışkanların küçük borular veya dar geçitler içinden aktığı zaman karşılaşılmaktadır. Akımın laminer ya da türbülanslı olması hali, Reynolds sayısı adı verilen boyutsuz bir büyüklük ile ifade edilir. Reynolds sayısı, kesitteki hıza, kesitin çapına ve akışkanın viskozitesine bağlı olarak değişkenlik gösterir [13].

\section{SONLU ELEMANLAR YÖNTEMI}

Sonlu elemanlar yöntemi, mühendislik problemlerinin çözümünde kullanılan sayısal bir yöntemdir. Yapısal analiz, 1sı transferi, akışkan hareketi gibi problemleri çözerken sonlu elemanlar yönteminden faydalanılabilir. Karmaşık geometriler, yüklemeler ve malzeme özelliklerini içeren problemler için, analitik veya matematiksel çözümler elde etmek genellikle mümkün değildir. Bu yüzden, kabul edilebilir sonuçlar için, sonlu elemanlar yöntemi gibi, sayısal yöntemler sıklıkla kullanılmaktadır [14].

Ayrık sistemlerin genel çözümünden bahsetmek gerekirse, iki boyutlu bir yapı için 1'den 6'ya kadar düğ̈̈mler numaralandırılmıştır (Şekil 1). Bu düğümler yoluyla momentler sisteme etki edecek şekilde aktarılmış olur. Bir başlangıç noktası seçilip, her bir düğüm kendi içerisinde çözümlenecektir. I elemanı olarak etiketlenen kısım, 1, 2, 3 düğümlerindeki kuvvetlere maruz kalacağından, bu eleman için belirtilen 3 düğüm noktası için işlem yapılacaktır. Diğer elemanlar (II, III ve IV) için de aynı hesaplamalar yapılıp, bu sonuçlar birleştirilerek sisteme ait yer değiştirmeler (P yükünden kaynaklı) ve mesnet reaksiyonları, şekil göz önünde tutularak hesaplanacaktır [15].

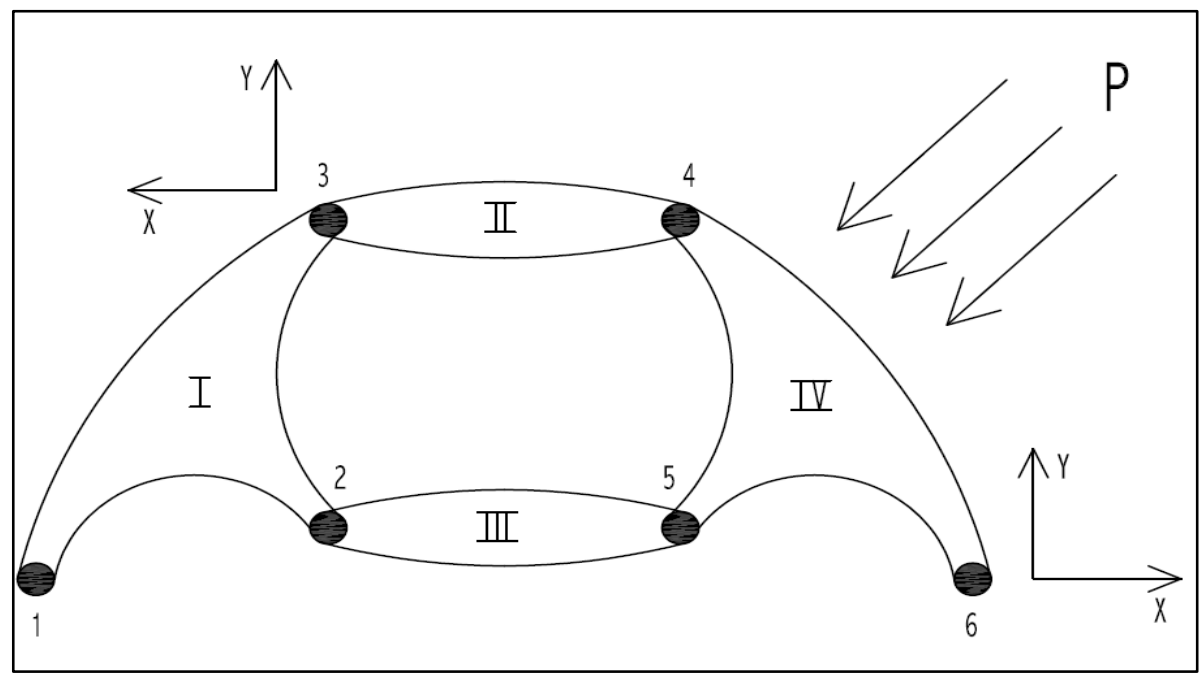

Şekil 1. Sonlu elemanlar yöntemi ile bölünmüs yapı elemanı gösterimi [15]

Sonlu elemanlar yöntemi ANSYS programının hücresel ağ yapısını oluştururken (mesh işlemi) kullanılan bir yöntem olmakla beraber, değişik geometriye sahip elemanlar için etkili sonuçlar vermektedir. Geometrisi verilen eleman için, sonlu elemanlar yöntemi ile çözümleme yapılmak istendiğinde, geometri küçük parçalara ayrılıp, sınır şartları atanarak, her bir nokta için çözümleme yapılır ve sonrasında elde edilen sonuçlar tek bir koordinat sisteminde ifade edilir [16].

\section{BULGU VE ANALIZLER}

ANSYS, sonlu elemanlar yöntemi alt yapısı ile çalışan, mühendislik problemlerinde çok tercih edilen bir paket programıdır. ANSYS, Workbench ve Apdl olmak üzere iki farklı ara yüz ile kullanıcıya 
çözüm sunmaktadır. Bu iki farklı ara yüz aynı sayısal model alt yapısıyla çalışmasına rağmen Workbench ekranı kullanıcıya sonuçları, renk aralıkları verilen ekran görüntüleri ile görsel olarak da destekleyerek vermektedir. Bu yüzden bu çalışmada Workbench ekranı tercih edilmiştir. Ayrıca model 3 boyutlu olarak hazırlandığı için Workbench ile sayısal analizinin yapılması tercih edilmiştir.

Workbench ara yüzü altında bulunan, Fluent modülü akışkanların fizik kurallarına uygun bir şekilde modellenmesini sağlamaktadır. Fluent modülünde, akış hareketleri, akışkanlar dinamiği alt yapısından bildiğimiz üç denklem kullanılarak modellenmektedir. Bunlar; kütlenin korunumu, enerjinin korunumu ve momentumun korunumu denklemleridir. Bu denklemler akış hareketinin daha gerçekçi bir biçimde incelenmesini sağlamaktadır.

Hidrolik yapılarda, Fluent modülü kullanılarak akış hareketleri daha etkili bir şekilde modellenmektedir. Böylelikle bu yapılarda akışkanın nasıl hareket edeceği ve bu hareketin yapılardaki sonuçları doğru bir şekilde öngörülebilecektir.

Şekil 2'de Darıderesi II Göleti dip savak yapısının, projede verilen gerçek boyutlara uygun olarak hazırlanan modeli verilmiştir. Dip savak yapısı 3 boyutlu modeli AutoCAD çizim programında modellenerek, ANSYS programına aktarılmıştır. ANSYS programı alt yapısında bulunan modüllerden biri olan ve akış hareketlerini inceleyen Fluent modülü içerisine, AutoCAD programından aktarılan model tanımlanmıştır. AutoCAD'de oluşturulan dip savak yapısına ait 3 boyutlu model görüntüsü, ANSYS Workbench ekranından alınmıştır.

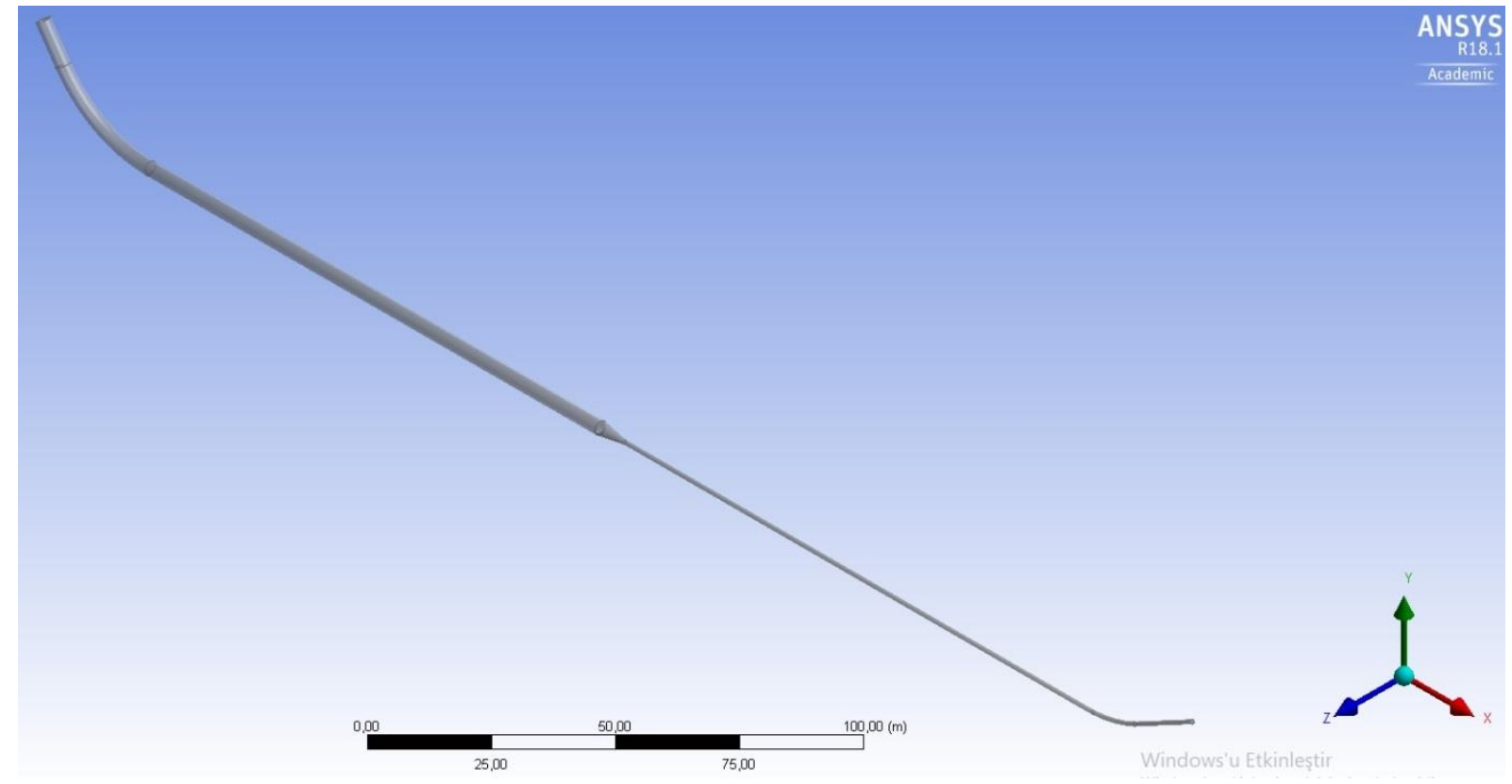

Şekil 2. ANSYS workbench ekranından alınan 3 boyutlu dip savak modeli

ANSYS'e aktarılan modele ait mesh görüntüsü Şekil 3'de görülmektedir. Mesh kısmında, model hücrelere ayrılmıştır. Mesh kısmı ya da hücrelere ayırma kısmı çözümün gerçeğe yakın sonuç vermesi anlamında büyük önem taşımaktadır. Oluşturulan mesh bölümleri sayıca ne kadar çoksa ve aynı zamanda kesitlerin daraldığı ya da değişiklik gösterdiği noktalarda ne kadar hassas ise sonuç o kadar gerçeğe yaklaşacağından, en gerçekçi çözümü elde edebilmek için 562111 tane hücreyle sonlu elemanlarla çözüm yapılmıştır. Herhangi bir bağlantı elamanı (bulon, vida vb.) bulunmadığı için mesh sayısı ve yapısı yeterli bulunmuştur. 


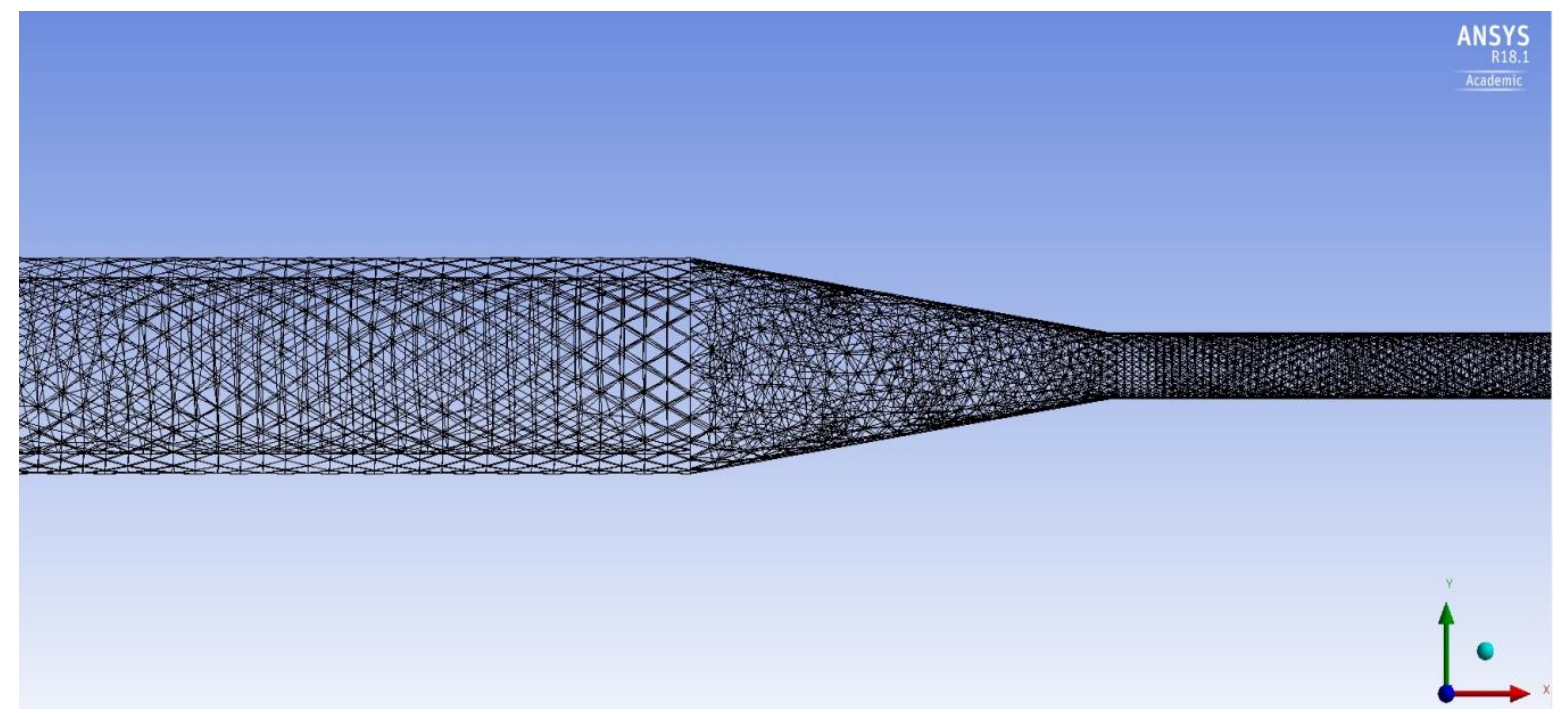

Şekil 3. Modele ait ANSYS mesh görüntüsü

Setup kısmında ise akışa ait özellikler belirlenmektedir. Bu model için türbülanslı ve laminer akış halleri ayrı ayrı modellenmiştir. Daha sonra suyun giriş ve çıkış kesitleri tanımlanmıştır. Ayrıca kesit içerisinde bulunan akışkan türü olan su için, ANSYS'in Fluent kütüphanesinde bulunan, suyun özgül kütlesi, yoğunluğu gibi özellikleri seçilmiştir. Suyun temas halinde olduğu boru için de, projede belirtilen St 37 çeliği özellikleri yine Fluent kütüphanesinden alınmıştır. Modele ait giriş basınç değeri ise, dip savak yapısına ait hidrolik hesaplamalardan elde edilerek $5001 \mathrm{~Pa}$ olarak tanımlanmıştır.

Sınır şartları ve akışa ait özellikler belirlendikten sonra çözüme geçilmiştir. Çözüm ve sonuç kısmında 3 boyutlu türbülanslı modele ait toplam basınç miktarı, hız büyüklükleri ve boruya ait kesme gerilme değerlerinin ANSYS Fluent ekran görüntüleri Şekil 4,5 ve 6'da verilmiştir.

Dip savak yapısına ait toplam basınç değerleri Şekil 4'te gösterilmiştir. Basınçlı borularda oluşabilecek kavitasyonu önlemek için dip savak yapısında toplam basınç negatif değere düşmemelidir. Kesitin daraldığı çıkış bölgesinde basınç değeri oldukça düşüktür. Bunun sebebi, kesitin atmosfere açılmasındandır. Hızın yüksek olduğu türbülanslı akımlarda dip savak yapısının hiçbir bölgesinde negatif basınç gözlenmemiştir.

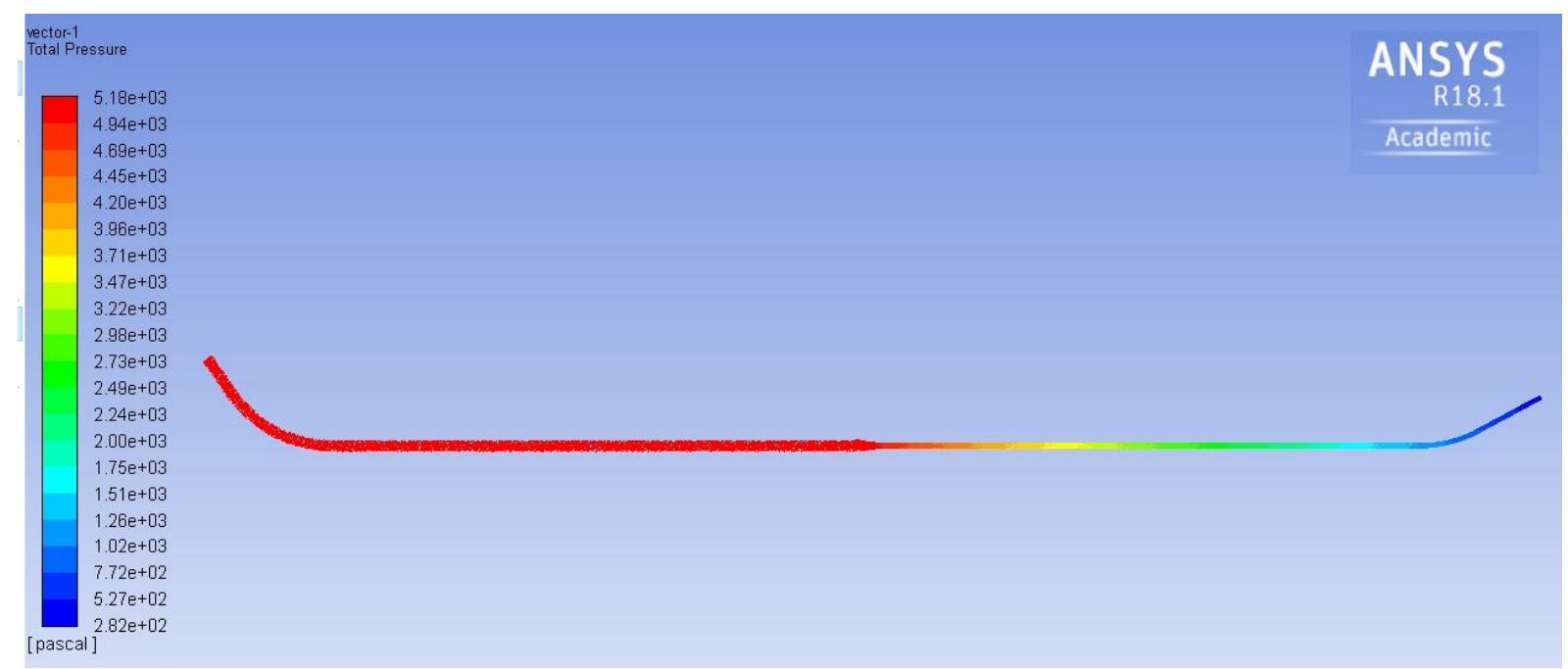

Şekil 4. Türbülanslı akım hali için toplam basınç değerleri 
Şekil 5'te hız değerlerinin değişimi görülmektedir. Verilen renk skalasına göre, dip savak yapısı giriş bölgesinde çap, çıkış kesitindeki çaptan daha büyük olduğu için hız dağılımı daha küçük değerler alırken; en yüksek hız değeri atmosfere açıldığı çıkış kesitinde oluşmaktadır.

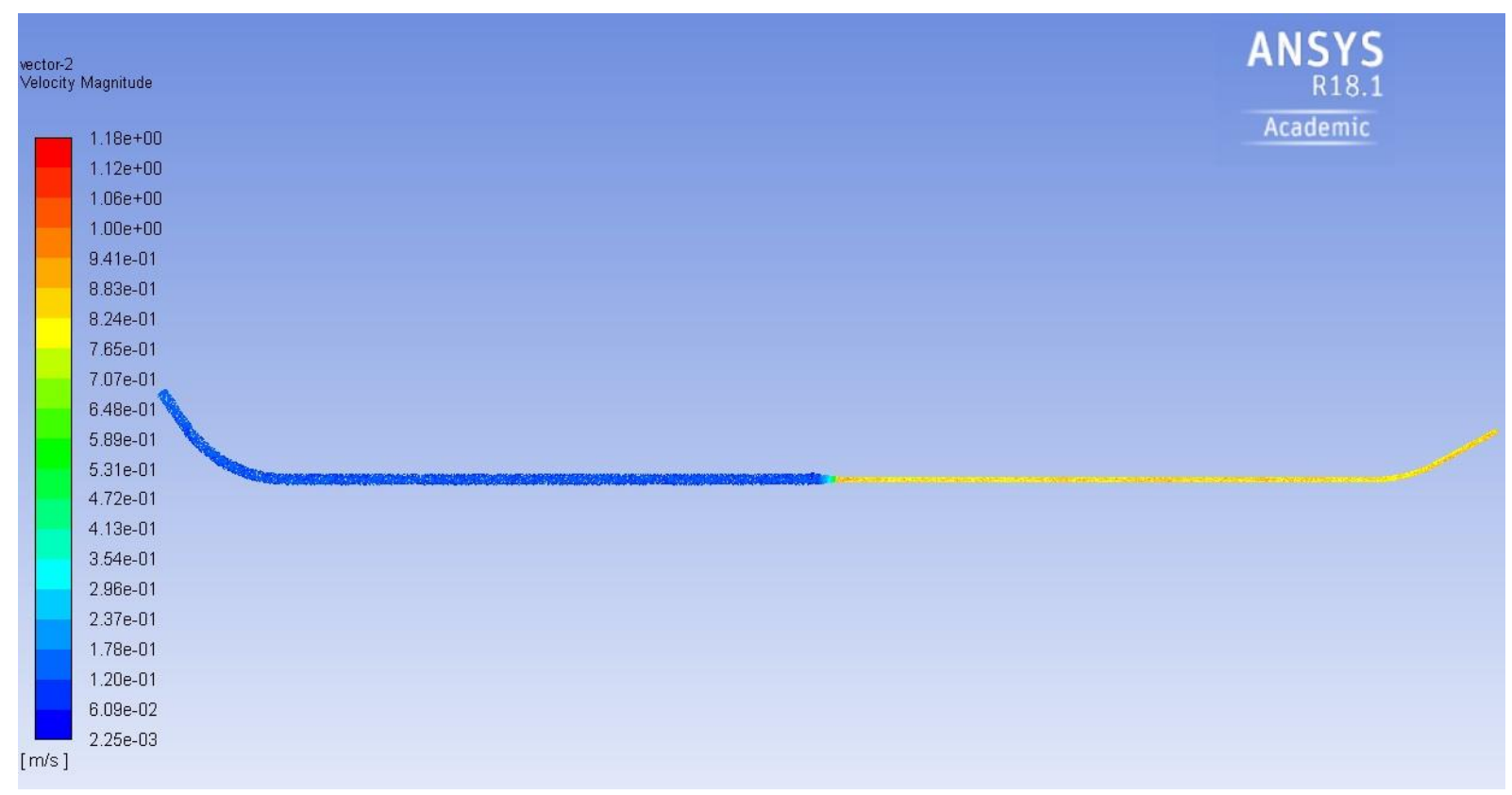

Şekil 5. Türbülanslı akım hali için hız büyüklük değerleri

Son olarak Şekil 6'da verilen boruya ait kesme gerilme değerini ise, suyun etkisinin boruda oluşturduğu kuvvet olarak ifade etmek mümkündür. Kesitin daraldığı bölgelerde, kesme gerilme değeri artış göstermektedir.

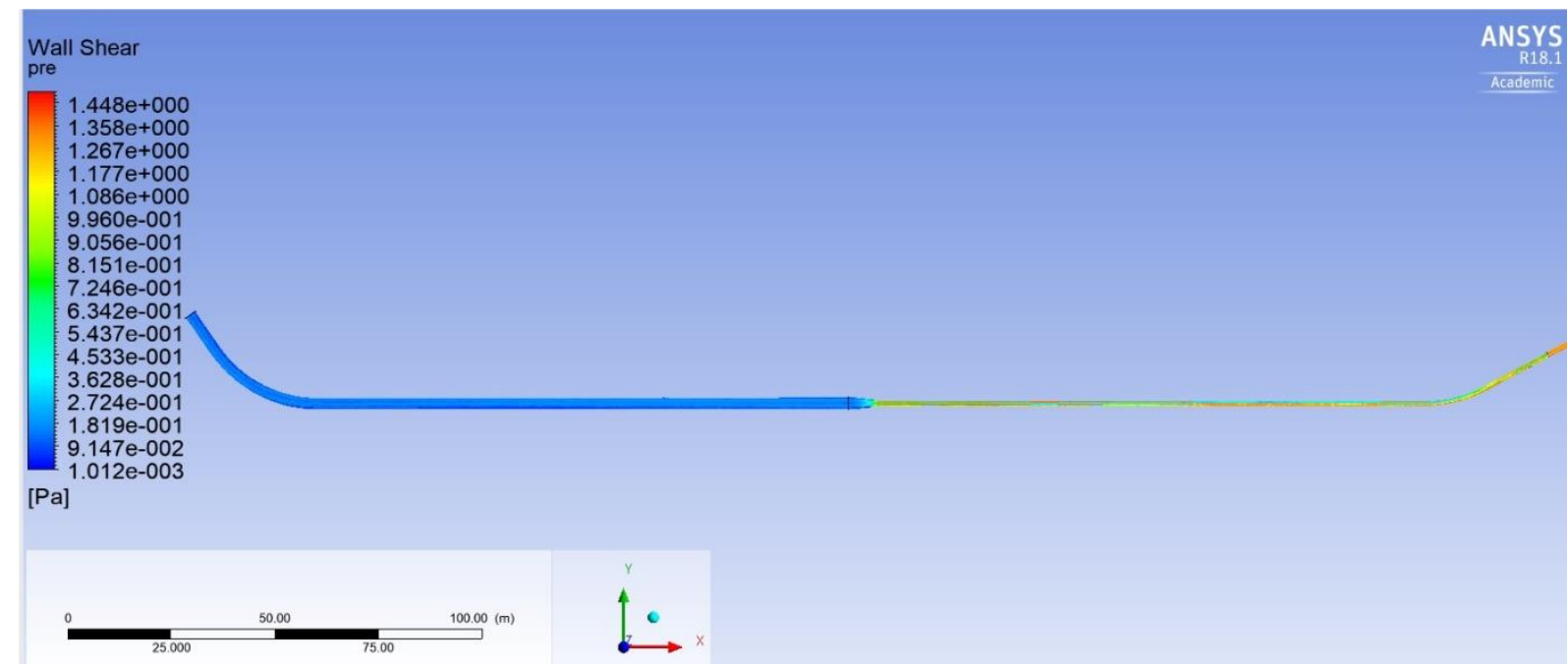

Şekil 6. Türbülanslı akım hali için boruya ait kesme gerilme değerleri

Aynı dip savak yapısına ait ancak bu kez laminer akım oluşması halinde yapıda meydana gelen toplam basınç, hız büyüklükleri ve boruya ait kesme değerleri aşağıdaki şekillerde verilmiştir (Şekil 7, 8 ve 9).

Şekil 7'de laminer akım hali için dip savak yapısında oluşan basınç değerleri türbülanslı akım halindeki değerlerden daha düşük olarak gözlenmiştir. Hızın düşük olduğu laminer akım halinde dip savak yapısında ortalama sıfira yakın değerler elde edilmiştir. 


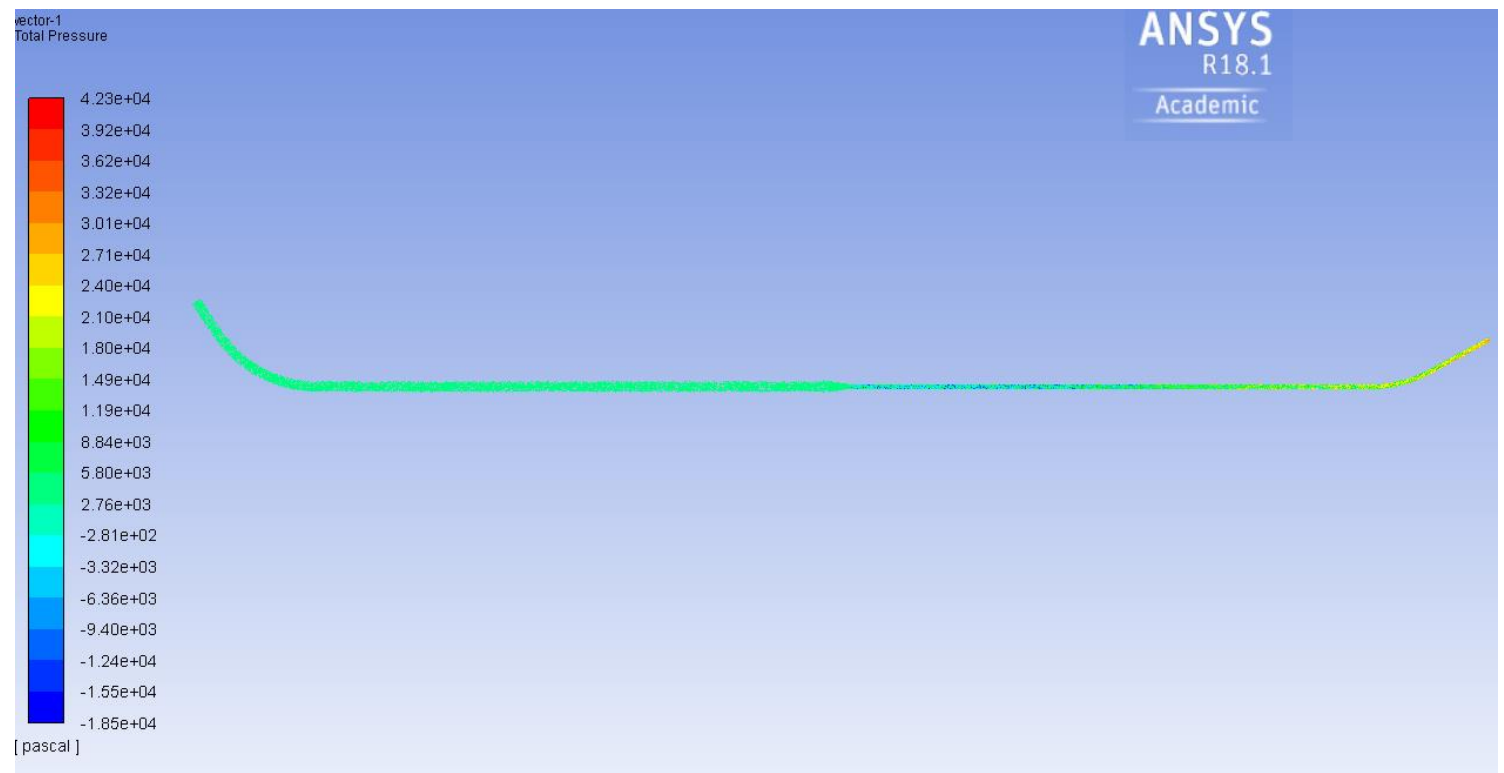

Şekil 7. Laminer akım hali için toplam basinç değerleri

Şekil 8'te hız değerlerinin değişimi Şekil 5'de verilen türbülanslı akım hali hız değişimine paralel bir değişim sergilemektedir. Ancak ortalama hız değerleri türbülanslı akım halindeki hız değerlerinden daha düşük bulunmuştur. Benzer şekilde, dip savak yapısı giriş bölgesinde çap, çıkış kesitindeki çaptan daha büyük olduğu için hız dağılımı daha küçük değerler alırken; en yüksek hız değeri atmosfere açıldığı çıkış kesitinde oluşmaktadır.

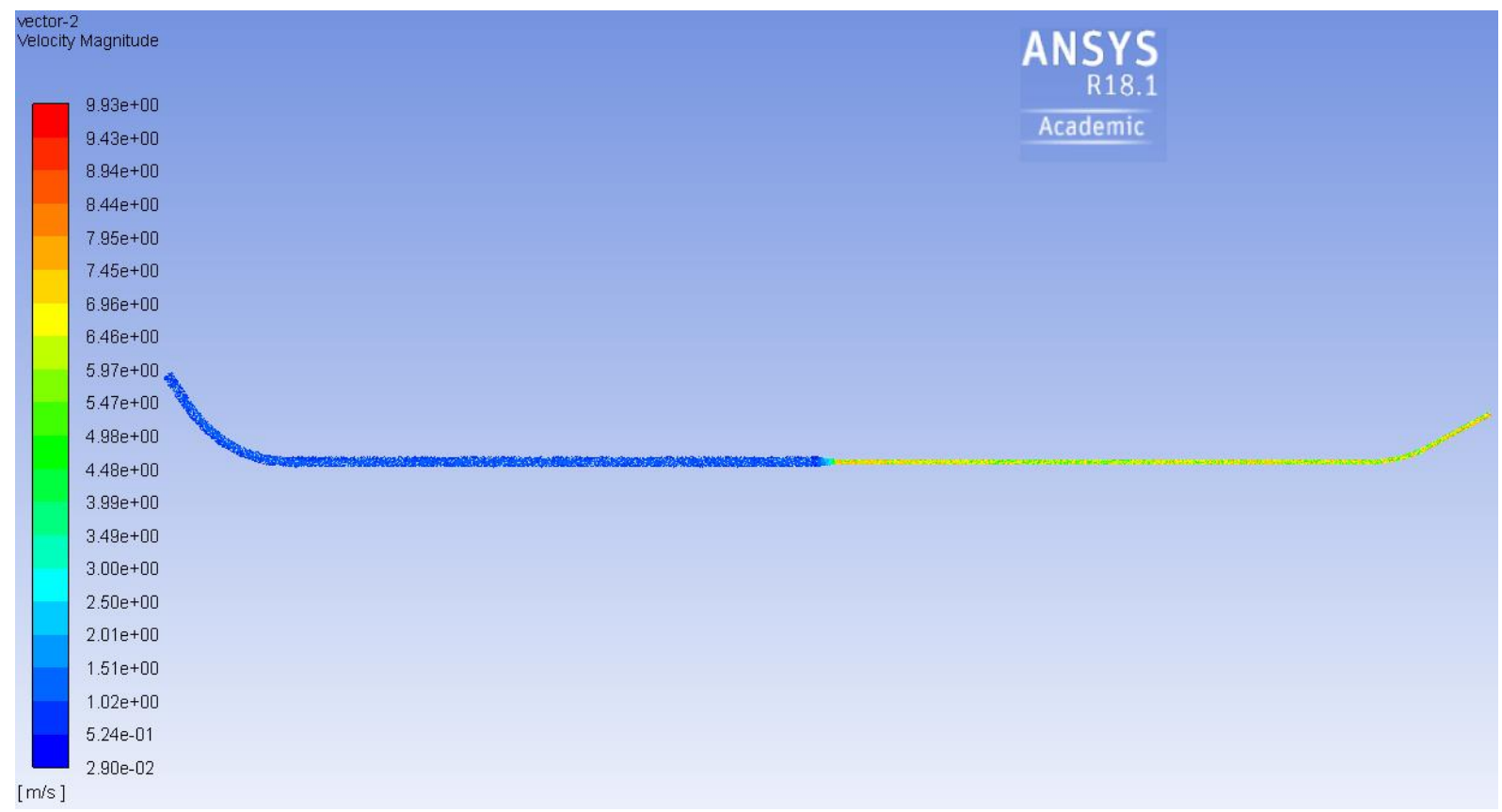

Şekil 8. Laminer akım hali için hız büyüklük değerleri

Şekil 9'da verilen boruya ait kesme gerilme değeri ise, türbülanslı akıma benzer şekilde kesitin daraldığı bölgelerde, kesme gerilme değeri artış göstermektedir. Türbülanslı akımda çalkantı kayma gerilmelerinin etkisiyle toplam kesme gerilmesi laminer akıma göre daha yüksek değerler almaktadır. 


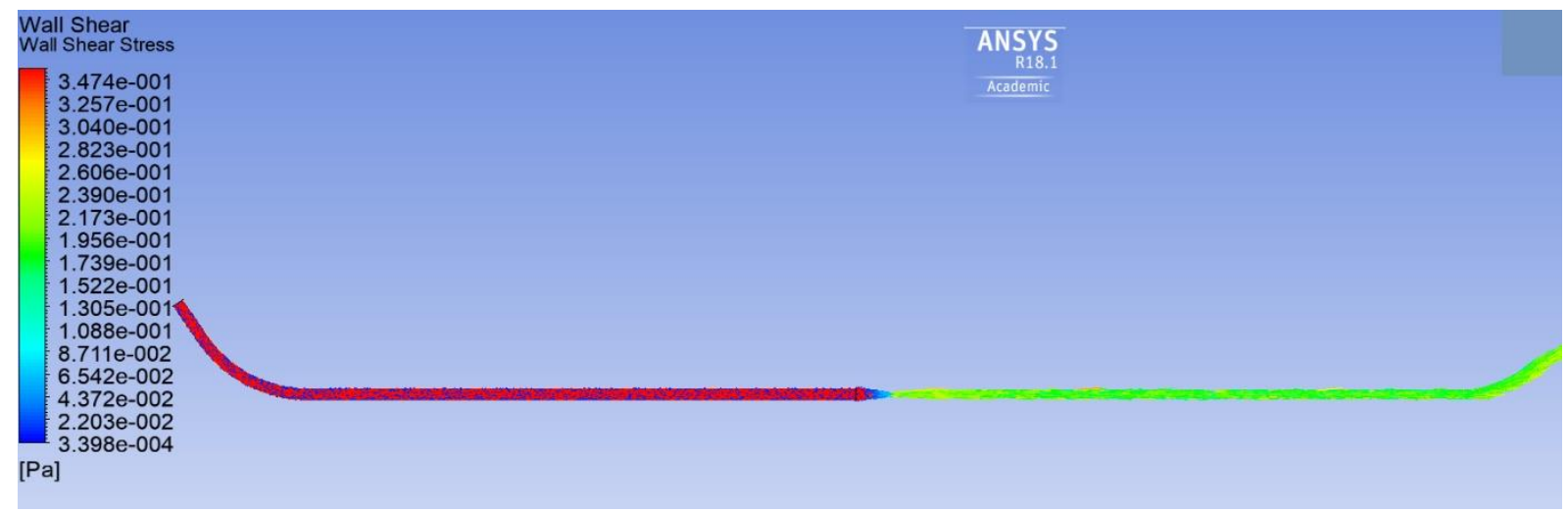

Şekil 9. Laminer akım hali için boruya ait kesme gerilme değerleri

Darıderesi II Göleti dip savak yapısında oluşan en yüksek hız büyüklükleri, toplam basınç ve kesme gerilmesi değerlerinin değişimi laminer ve türbülanslı akım hali için Tablo 2'de verilmiştir.

Tablo 2. Darıderesi II Göleti Toplam Basınç, Hız Büyüklükleri ve Kesme Gerilmesi Maksimum Değerleri

\begin{tabular}{lccc} 
Toplam Basınç & $\begin{array}{c}\text { Hız } \\
\text { Büyüklük } \\
\text { Değeri } \\
(\mathrm{m} / \mathrm{sn})\end{array}$ & $\begin{array}{c}\text { Kesme } \\
\text { Gerilme } \\
\text { Değeri } \\
(\mathrm{Pa})\end{array}$ \\
\hline Türbülanslı Akım & $5.18 \mathrm{e}+03$ & 1.18 & 1.448 \\
\hline Laminer Akım & $4.23 \mathrm{e}+04$ & 9.93 & $3.47 \mathrm{e}-001$ \\
\hline
\end{tabular}

\section{SONUCLAR}

Büyük su yapıları için, oluşturulan modellerde, basınç, hız gibi kinetik büyüklüklerin gözlenmesi önemlidir. Bu çalışmada hidrolik yapılar için kullanılan ANSYS programı FLUENT modülü ile, 3 boyutlu akış modeli geliştirilmiştir. Darıderesi II Göleti dip savak yapısına ait türbülanslı ve laminer akım halleri için, toplam basınç, hız büyüklüğü ve kesme gerilme değerleri elde edilmiştir. Böylelikle su kaynaklarının ve yapılarının planlanması ve projelendirilmesi aşamasında, oluşabilecek maksimum ve minimum kinetik büyüklükler hakkında bilgi sahibi olunacaktır. Modelleme sonuçlarına göre en olumsuz senaryolar göz önünde bulundurularak hidrolik yapıya ait boyutlar deneysel hiçbir düzeneğe ihtiyaç duyulmadan, kolaylıkla değiştirilebilecektir.

Çalışmada, laminer ve türbülanslı akım hali için kıyaslamalı olarak verilen değerlerden görüldüğü üzere; baraj yapılarında bulunan dip savakların, türbülanslı hal için incelenmesi daha gerçekçi bir durum oluşturacaktır. Toplam basınç değerini incelemek gerekirse sınır şartları kısmında toplam basınç değeri $5001 \mathrm{~Pa}$ alınmıştır. Bu değer türbülanslı akım hali için neredeyse sabit kalmaktayken, laminer akım için değişiklik göstermiştir. Bu değerin değişiklik göstermesi de hız ve kesme gerilme değerlerini farklılaştırmıştır. Çalışmada geliştirilen model için hidrolik şartnameden hesaplanan toplam basınç değerini ve aynı zamanda bu sınır şartını sağlamasından dolayı türbülanslı akım halini seçmek daha gerçekçi bir sonuç verecektir. Çünkü ölü hacmin üzerindeki suyu yüksek hız değerleri ile mansap kısmına aktaran dip savaklarda türbülanslı akış gözlenmektedir.

Bu çalışmada elde edilen sonuçlar, bölgede yapılacak olan diğer gölet ya da baraj yapıları için kaynak niteliği taşıyabilir. Ayrıca, yapılacak olan diğer çalışmalar için oluşturulan model farklı senaryolarla yeniden değerlendirilebilir. 


\section{KAYNAKLAR}

[1] M. C. Aydın, A. E. Ulu and Ç. Karaduman, "CFD analysis of Ilısu Dam sluice outlet," Firat University Turkish Journal of Science \& Technology, vol. 13, no. 1, pp. 119-124, 2018.

[2] S. Li, S. Cain, M. Wosnik, C. Miller, H. Kocahan and R. Wyckoff, "Numerical modeling of probable maximum flood flowing through a system of spillways," Journal of Hydraulic Engineering, vol. 137, no. 1, pp. 66-74, 2011.

[3] M. Alihosseini and P. U. Thamsen, "Numerical and experimental investigation of flow in partially filled sewer pipes," Technische Mechanik. Scientific Journal for Fundamentals and Applications of Engineering Mechanics, vol. 39, no. 1, pp. 113-124, 2019.

[4] M. Yaylacı ve C. Terzi, "Temas problemlerinde sonlu elemanlar yönteminin doğruluğunun incelenmesi," Mühendislik Bilimleri ve Tasarım Dergisi, c. 6, s. 3, ss. 511-519, 2018.

[5] N. Yılmaz ve İ. Çiçek, "Standart test pervanesi analizleri ile hesaplamalı akışkanlar dinamiği analiz altyapısının doğrulanması," Mühendislik Bilimleri ve Tasarım Dergisi, c. 6, s. 4, ss. 681-690, 2017.

[6] N. A. Beg, R. F. Carvalho, J. Leandro, P. Lopes and L. Cartaxo, "Investigation of the flow field inside a drainage system: Gully-Pipe-Manhole," presented at 6th International Junior Researcher and Engineer Workshop on Hydraulic Structures, 2016, Lübeck, Germany, 2016.

[7] P. Lopes, J. Leandro, R. F. Carvalho, P. Páscoa and R. Martins, "Numerical and experimental investigation of a gully under surcharge conditions," Urban Water Journal, vol. 12, no. 6, pp. 468476, 2015.

[8] S. Kumar and A. K. Pentakota, "Computational fluid dynamics simulations of pipe elbow flow," International Journal of Professional Engineering Studies, vol. 9, no. 2, pp. 32-42, 2017.

[9] M. Patel. (2020, September 17). CFD Modeling Services [Online]. Available: https://cfdmodelingservices.wordpress.com/2013/06/12/4-advantages-and-disadvantages-of-cfd/.

[10] S. Chandra, "Computational fluid dynamics analysis of rectangular microchannel heat sink," Ph.D. dissertation, Delhi College of Engineering, Delhi Technological University, Delhi, India, 2017.

[11] U. C. Liestyarini, "CFD Analysis internal pipe flow," M.S. thesis, Offshore Technology / Subsea Technology, Faculty of Science and Technology, University of Stavanger, Stavanger, Norway, 2016.

[12] H.K. Versteeg and W. Malalasekera, An Introduction to Computational Fluid Dynamics, England: Pearson Education Limited, 2007.

[13] M. Sümer, İ. Ünsal ve M. Bayazıt, Hidrolik, İstanbul, Türkiye: Birsen Yayınevi, 2013.

[14] D.L. Logan, A First Course in The Finite Element Method, Canada: Thomson, 2007.

[15] O.C. Zienkiewicz, The Finite Element Method, England: Tata Mcgraw Hill, 2001.

[16] T. Aydın, "Darıderesi II Göleti'nin dinamik analizlerinin ANSYS ile incelenmesi," Yüksek Lisans tezi, Fen Bilimleri Enstitüsü, Süleyman Demirel Üniversitesi, Isparta, Türkiye, 2017. 